\title{
Clinicopathological significance of cyclooxygenase-2 expression in hypopharyngeal squamous cell carcinoma
}

\author{
RIEKO GOTO ${ }^{1}$, HIROSHI HOSHIKAWA ${ }^{1}$, TAKASHI FUJI' ${ }^{2}$, KANAKO INDO $^{3}$, \\ KUNITOSHI YOSHINO ${ }^{2}$, KATSUMI IMAIDA ${ }^{4}$ and NOZOMU MORI ${ }^{1}$
}

\author{
${ }^{1}$ Department of Otolaryngology, Faculty of Medicine, Kagawa University, 1750-1 Ikenobe, Miki-cho, \\ Kita-gun 761-0793; ${ }^{2}$ Department of Otolaryngology, Osaka Medical Center for Cancer and Cardiovascular \\ Diseases, 1-3-3 Nakamichi, Higashinari-ku, Osaka 537-8511; ${ }^{3}$ Department of Otolaryngology, Takamatsu \\ Red Cross Hospital, 4-1-3 Ban-cho, Takamatsu 760-0017; ${ }^{4}$ Onco-Pathology, Department of Pathology and \\ Host-Defense, Faculty of Medicine, Kagawa University, 1750-1 Ikenobe, Miki-cho, Kita-gun, Kagawa 761-0793, Japan
}

Received October 5, 2007; Accepted November 29, 2007

\begin{abstract}
The purpose of this study was to determine the expression of cyclooxygenase- 2 (COX-2) in normal epithelium, dysplasia and squamous cell carcinoma of the hypopharynx and to investigate associations with clinicopathological factors and survival. Seventy-five patients with hypopharyngeal squamous cell carcinomas (HPSCC) who underwent surgical treatment at the Department of Otolaryngology, Osaka Medical Center for Cancer and Cardiovascular Diseases, were investigated. COX-2 expression was determined by immunohistochemistry and $97.3 \%(73 / 75)$ of samples displayed immunostaining in tumor cells. COX-2 staining was localized mainly in the cytoplasm (73/75) and was rare in stromal cells (2/75). Over half of the areas of dysplastic cells adjacent to carcinomas also showed COX-2 staining $(41 / 70,58.6 \%)$. There were no significant correlations between the COX-2 expression and tumor size, location and tumor growth type, T- and N-stage, tumor recurrence, lymph node metastasis and survival in this study. COX-2 expression thus does not appear to have a prognostic significance for hypopharyngeal SCC although there was a tendency for higher values in T3/T4 than T1/T2 cases. Furthermore, COX-2 was found to be more strongly expressed in poorly-differentiated than in moderately/welldifferentiated carcinomas. In this study group, COX-2 was up-regulated not only in SCCs but also in the dysplastic lesions of the hypopharynx, suggesting that COX-2 inhibition may be a useful chemopreventive strategy.
\end{abstract}

Correspondence to: Dr Rieko Goto, Department of Otolaryngology, Faculty of Medicine, Kagawa University, 1750-1 Ikenobe, Miki-cho, Kita-gun, Kagawa 761-0793, Japan

E-mail: blue@med.kagawa-u.ac.jp

Key words: cyclooxygenase-2, hypopharynx, squamous cell carcinoma, dysplasia

\section{Introduction}

The hypopharyngeal squamous cell carcinoma is relatively aggressive among head and neck carcinomas with a very poor overall prognosis due to loco-regional recurrence and metastasis to lymph nodes despite advances in surgery, radiotherapy and chemotherapy. Therefore, new effective treatment strategies are needed.

Cyclooxygenases (COX) are rate-limiting enzymes converting arachidonic acid to prostaglandin. The two isoforms are characterized as COX-1 and -2 . COX-1 is constitutively expressed in most tissues and mediates the synthesis of prostaglandins to control normal physiological functions, whereas the COX-2 expression is generally not detectable but is rapidly induced by various stimuli such as inflammatory reactions, growth factors, oncogenes and tumor promoters $(1,2)$.

COX-2 is expressed in various tumor types and is now generally considered to promote the carcinogenesis and growth of established tumors. There is evidence that a prolonged COX-2 inhibition by aspirin or other non-steroidal anti-inflammatory drugs (NSAIDs) offers protection against colon cancer and other malignancies $(3,4)$. COX-2 inhibitors have been shown to inhibit the proliferation of tumor cells in vitro and in vivo and to act in part by inducing tumor cell apoptosis.

Overexpression of COX-2 is found in the carcinomas of various organs, including the colon $(5,6)$, lung $(7)$, bladder (8), esophagus (9-14) and head and neck (15-18). Up-regulation in laryngeal (19-22), tongue (23) and oropharyngeal cancers (24) has been reported at the mRNA and protein levels. However, data are rather limited regarding hypopharyngeal cancers (15). Furthermore, the prognostic significance for COX-2 has been shown, but mainly for adenocarcinomas (26) and results for squamous cell carcinomas are equivocal (12).

We examined the COX-2 expression in hypopharyngeal squamous cell carcinomas and investigated the relationships with clinicopathological and prognostic parameters. 


\section{Materials and methods}

Patients. Our subjects were 86 patients with hypopharyngeal squamous cell carcinomas undergoing surgical treatment of primary tumors at the Department of Otolaryngology, Osaka Medical Center for Cancer and Cardiovascular Diseases, from January 1995 through December 2000. After receiving informed consent, medical records and surgical specimens were collected from all but nine patients, who were excluded as the samples were inadequate or of special histopathology (one adeno-squamous and one basaloid lesion). The 75 cases of HPSCC (64 men, 85.3\% and 11 women, 14.7\%) had a mean age at surgery of 64.0 years (range: $36-85$ ). The classification of tumor size, lymph node status and stage grouping was performed according to the 1988 UICC criteria. The data collected for each patient included age, sex, tumor site, Brinkman index, Sake index, tumor growth type, treatment method, tumor recurrence, cause of death (where appropriate) and survival outcome. Histological grading (well-, moderately- and poorly-differentiated) was performed with H\&E stained sections by a pathologist at the Osaka Medical Center for Cancer and Cardiovascular Diseases. The details of patient and tumor characteristics are given in Table I. One patient received preoperative chemo- and radiotherapy and four patients underwent surgery for recurrent lesions after radical chemo- and/or radiotherapy and three cases had radiotherapy of the hypopharynx for another disease. During the follow-up period, local recurrence occurred in 5 cases $(6.7 \%)$, lymph node recurrence in $16(21.3 \%)$ and distant metastasis in $9(12 \%)$. An extended follow-up was possible for 66 patients and 5-year survivors numbered 20.

Pretreatment. All block samples were fixed in formalin and were cut into 7-mm slices for decalcification and fixation. Sections of $4 \mu \mathrm{m}$ thickness were cut from tissues embedded in paraffin wax and routinely processed. As a pretreatment for immunohistochemistry, heating for $15 \mathrm{~min}$ at $100^{\circ} \mathrm{C}$ in citrate buffer ( $\mathrm{pH} 7.0)$ was performed in a microwave, followed by washing in PBS buffer ( $\mathrm{pH} 7.5$ ) for $5 \mathrm{~min}$.

Immunohistochemistry. The Ventana NX System ${ }^{\circledR}$ (Ventana I-View DAB Universal kit ${ }^{\circledR}$ ) was employed for immunohistochemistry, with anti-COX-2 Ab (160112:Cayman Chemical, 1:100) as the primary antibody. Scoring of the immunohistochemical staining results was performed by a single pathologist blinded to the patient status (clinical parameters). The intensity of staining was graded from 0 to 3 : 0 , negative; 1 , weakly positive; 2 , moderately positive and 3 , strongly positive. The area of stained cells was also graded from 0 to 4 : $0,0 \% ; 1,1-25 \% ; 2,26-50 \% ; 3,51-75 \%$ and 4 , $76-100 \%$. The degree of staining (0-12) was then calculated as the product of the intensity and area of stained cells.

The pattern of tumor infiltration according to digestive organ cancer (INF- $\alpha-\beta-\gamma$ ) and the COX-2 relative staining score $(-3$ to +3$)$ in tumor invasion fronts as compared to the main tumor lesion were identified and investigated, as well as the relationship to the clinical data.

Statistical analysis. Statistical analysis was performed using StatView 5.0 (Abacus Concepts, Inc., Berkeley, CA). Clinical
Table I. Patient characteristics.

\begin{tabular}{|c|c|c|}
\hline Characteristics & No. & $\%$ \\
\hline Total & 75 & \\
\hline \multicolumn{3}{|l|}{ Sex } \\
\hline Male & 64 & 85.3 \\
\hline Female & 11 & 14.7 \\
\hline Age at surgery (years) & $64.0(36-85)$ & \\
\hline \multicolumn{3}{|l|}{ Tumor stage } \\
\hline $\mathrm{T} 1$ & 3 & 4.0 \\
\hline $\mathrm{T} 2$ & 31 & 41.3 \\
\hline $\mathrm{T} 3$ & 17 & 22.7 \\
\hline $\mathrm{T} 4$ & 24 & 32.0 \\
\hline \multicolumn{3}{|l|}{ Nodal stage } \\
\hline NO & 20 & 26.7 \\
\hline N1 & 14 & 18.7 \\
\hline $\mathrm{N} 2$ & 38 & 50.7 \\
\hline N3 & 3 & 4.0 \\
\hline \multicolumn{3}{|c|}{ Pathological differentiation } \\
\hline Well & 23 & 30.7 \\
\hline Moderate & 37 & 49.3 \\
\hline Poor & 10 & 13.3 \\
\hline NOS & 5 & 6.7 \\
\hline \multicolumn{3}{|l|}{ Recurrence } \\
\hline Local & 5 & 6.7 \\
\hline Lymph node & 16 & 1.3 \\
\hline Distant & 9 & 12.0 \\
\hline Alive (recurrence-free) & 25 & 33.3 \\
\hline 5-year survival & 20 & 26.7 \\
\hline Smoker & 64 & 85.3 \\
\hline Brinkman index & $930.2(40-3120)$ & \\
\hline Drinker & 65 & 86.7 \\
\hline Sake index & $101.0(32-370)$ & \\
\hline
\end{tabular}

and histopathological parameters were analyzed using the Mann-Whitney U test and the Kruskal-Wallis test (nonparametric analysis of variance) and differences were considered significant at $\mathrm{p}<0.05$. Overall survival was estimated according to the Kaplan-Meier method (BreslowGehan-Wilcoxon) and differences in survival were evaluated by the log-rank test.

\section{Results}

Immunohistochemical analysis of $C O X-2$. The samples $(97.3 \%, 73 / 75)$ displayed COX-2 immunostaining in tumor cells of which $10(13.3 \%), 35(46.7 \%)$ and 28 (37.3\%) showed a strong, moderate and weak expression, respectively. COX-2 staining was localized mainly in the cytoplasm of tumor cells $(73 / 75)$ and only infrequently found in stromal cells (2/75). 

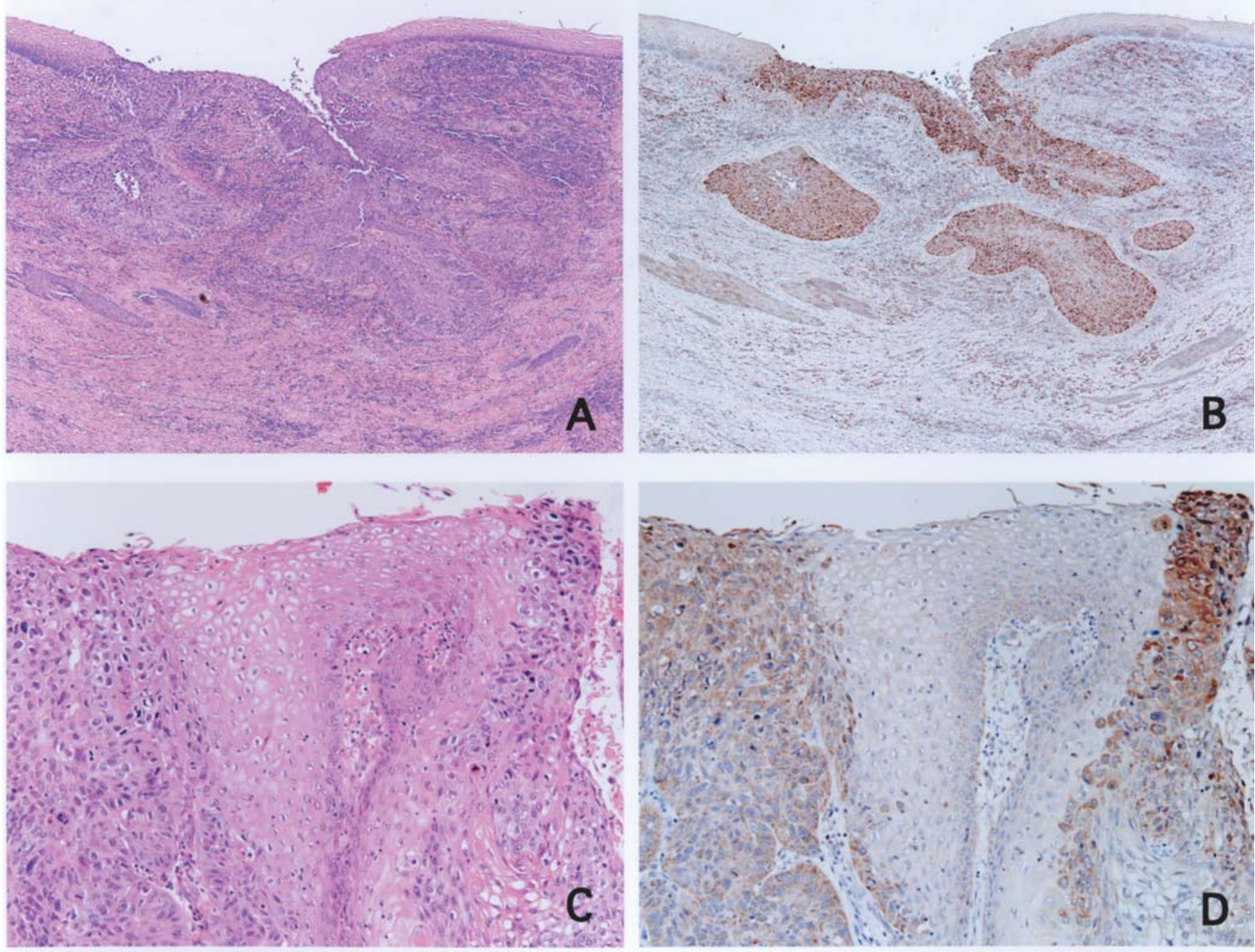

Figure 1. H\&E staining (A and C) and COX-2 immunohistochemistry (B and D) of the normal epithelium, a dysplastic area and a squamous cell carcinoma of hypophaynx. Note COX-2 staining in the dysplasia and carcinoma, including an invasive front (B). Strong COX-2 staining in carcinoma. On the other hand, the normal epithelium is negative (D). Magnification: $\mathrm{x} 40$ (A and B) and $\mathrm{x} 100(\mathrm{C}$ and D).

Table II. The association between COX-2 staining and pathology.

\begin{tabular}{lrrrrrr}
\hline & & & \multicolumn{4}{c}{$\begin{array}{c}\text { COX-2 positive } \\
\text { (intensity of staining) }\end{array}$} \\
\cline { 4 - 7 } Pathology & No. & COX-2+(\%) & \multicolumn{1}{c}{0} & 1 & 2 & 3 \\
\hline Normal & 75 & $1(1.30)$ & 74 & 1 & 0 & 0 \\
Dysplasia & 70 & $41(58.6)$ & 29 & 39 & 2 & 0 \\
SCC & 75 & $73(97.3)$ & 2 & 28 & 35 & 10 \\
\hline
\end{tabular}

In the dysplastic areas adjacent to carcinomas, $58.6 \%(41 / 70)$ of samples showed COX-2 staining of which $2(2.9 \%)$ and $39(55.7 \%)$ showed a moderate and weak expression, respectively. There was only $1.3 \%(1 / 75) \mathrm{COX}-2$ staining in the normal squamous cells around the tumor area (Table II). Representative COX-2 immunostaining patterns in hypopharyngeal SCCs and dysplastic cells adjacent to carcinomas are shown in Fig. 1. A clear increase in COX-2 staining was evident from normal epithelium through to dysplasia and cancers. The COX-2 expression patterns in each degree of differentiation are shown in Fig. 2.

Correlation with clinicopathological parameters (Table III). There were no significant correlations between the COX-2 expression and tumor size, location, growth type, $\mathrm{T}$ - and $\mathrm{N}$ stage, recurrence, lymph node metastasis, or survival in this study. However, with the area of stained cells $(\mathrm{p}=0.086)$ and the degree of staining ( $\mathrm{p}=0.073$, not shown in Table), there was a tendency for higher values in T3/T4 than T1/T2. Smokers constituted 64 cases $(85.3 \%)$ and the average Brinkman index (Brinkman index $=$ numbers of cigarette smoked per day multiplied by years of smoking) was 930.2 (40-3120). The number of drinkers was 65 cases and the average Sake index (Sake index $=$ total grams of ethanol consumed per day/22 $\mathrm{g}$ multiplied by years of drinking) was 101.0 (32-370). The COX-2 expression did not correlate with either of these indices.

The intensity of COX-2 staining was significantly higher in the poorly-differentiated tumors than in the well/moderately- 

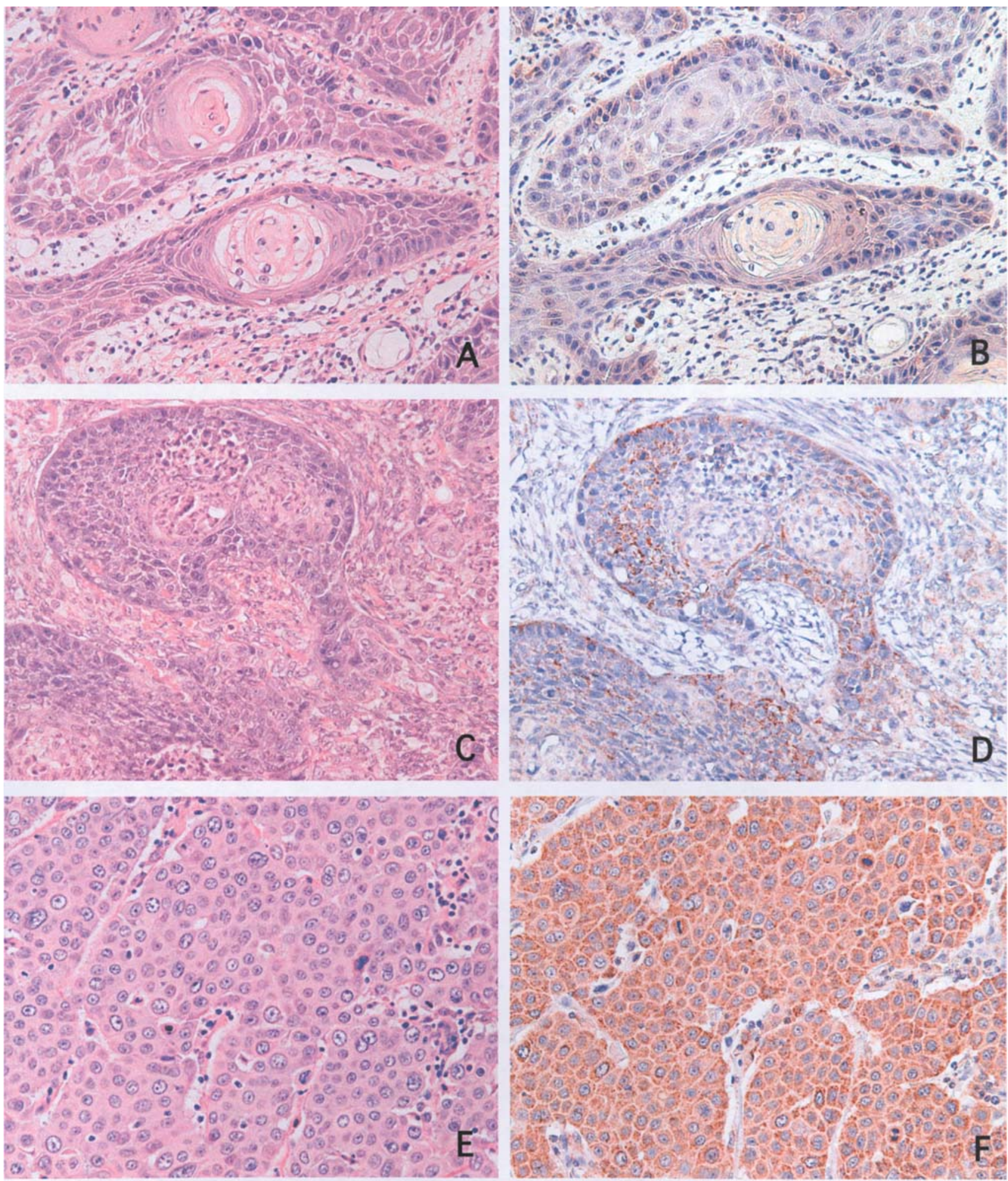

Figure 2. H\&E staining (A, C and E) and COX-2 immunohistochemistry (B, D and F) in hypopharyngeal carcinoma. Well (A and B), moderate (C and D) and poorly $(\mathrm{E}$ and $\mathrm{F}$ ) differentiated carcinomas are shown, respectively. The example of various intensities of COX-2 staining in cytoplasm. Weakly positive in welldifferentiated carcinomas (B). Moderately positive in moderately-differentiated carcinomas (D). Strong COX-2 staining in almost all areas of the tumor cells with poor differentiation (F). Magnification: x200.

differentiated lesions $(\mathrm{p}=0.039)$. However, no significant difference was found between poor- and well-differentiated carcinomas $(\mathrm{p}=0.087)$ and there was no relationship with the tumor infiltration pattern (INF- $\alpha-\beta-\gamma)$.

\section{Discussion}

In this study, the COX-2 expression was found to gradually increase with progressive tumorigenesis in the hypopharynx. 
Table III. Clinicopathological variables and COX-2 expression.

\begin{tabular}{|c|c|c|c|c|c|c|c|c|c|c|c|c|c|}
\hline \multirow{2}{*}{$\begin{array}{l}\text { Clinicopathological } \\
\text { variables }\end{array}$} & \multirow[b]{2}{*}{ No. } & \multirow[b]{2}{*}{$\mathrm{COX} 2^{+}$} & \multicolumn{5}{|c|}{ COX-2 intensity of staining } & \multicolumn{6}{|c|}{ COX -2 area of stained cells } \\
\hline & & & 0 & 1 & 2 & 3 & p-value & 0 & 1 & 2 & 3 & 4 & p-value \\
\hline \multicolumn{14}{|l|}{ Tumor stage } \\
\hline $\mathrm{T} 1 / \mathrm{T} 2$ & 34 & $33(97.1)$ & 1 & 16 & 13 & 4 & 0.163 & 1 & 2 & 6 & 7 & 18 & 0.086 \\
\hline T3/T4 & 41 & $40(97.6)$ & 1 & 12 & 22 & 6 & & 1 & 2 & 3 & 5 & 30 & \\
\hline \multicolumn{14}{|l|}{ Lymph nodes } \\
\hline Negative & 20 & $20(100)$ & 0 & 7 & 10 & 3 & 0.540 & 0 & 1 & 3 & 3 & 13 & 0.872 \\
\hline Positive & 55 & $53(96.4)$ & 2 & 21 & 25 & 7 & & 2 & 3 & 6 & 9 & 35 & \\
\hline \multicolumn{14}{|l|}{ Differentiation } \\
\hline Well/moderate & 60 & $58(96.7)$ & 2 & 23 & 29 & 6 & 0.039 & 2 & 2 & 6 & 10 & 40 & 0.201 \\
\hline Poor & 10 & $10(100)$ & 0 & 2 & 4 & 4 & & 0 & 2 & 2 & 1 & 5 & \\
\hline
\end{tabular}

The COX-2 expression was detectable in almost all hypopharyngeal SCCs and was higher in the adjacent dysplastic squamous epithelium than in normal tissue. The overexpression of COX-2 has been documented in various carcinomas, as well as in precancerous and dysplastic lesions $(7,14,27,28)$ and increases with the grade of dysplasia and progression $(16,23,29)$. It has been reported that mild-to-moderate COX-2 immunoreactivity was also present in the epithelial cells of normal-appearing oral mucosal epithelium adjacent to the head and neck SCCs and linked to the up-regulation of COX-2 mRNA (15). Thus this may be an early event in tumorigenesis. With hypopharyngeal carcinomas, COX-2 expression may also be detectable in tissues adjacent to cancer nests and the possibility was suggested that a chronic inflammatory reaction leads to the induction of COX-2 expression and the promotion of the development of carcinoma (25).

The clinicopathological significance of COX-2 expression in SCCs is controversial, despite a number of investigations of the esophageal $(11,12)$ and the head and neck $(21,22,24)$ lesions. In the current study, there was no clear relationship with clinicopathological parameters. There was a tendency for COX-2 expression to be higher in T3/T4 than T1/T2 lesions but there was no prognostic significance, in line with earlier findings $(6,17,22,27)$. Again the available data are conflicting. In various cancers, COX-2 overexpression is associated with a more malignant phenotype and worse prognosis $(9,24,29)$ following local relapse, lymph node $(20,26)$ and distant metastasis (18). In the single investigation of 23 hypopharyngeal carcinomas by RT-PCR analysis (25), the frequency of COX-2 overexpression was significantly higher in the N1-N3 group than in the N0 group. However, Raneletti et al (21) described COX-2 overexpression in less aggressive laryngeal SCCs. In the esophagus, a high COX-2 expression only appears to impact on the prognosis in adenocarcinomas (12), with no relation to the N stage, locoregional and distant metastasis and survival with SCCs.

The links with the degree of differentiation for SCCs of the esophagus $(9,11,30)$, cervix (31) and head and neck region $(17,23,29,32)$ are also unclear. In an earlier laryngeal study COX-2 was found to be strongly expressed in well- differentiated areas and apparently absent in very poorlydifferentiated tissue, the more node positive cases all being COX-2 negative (21). The authors concluded that the COX-2 expression is lost when laryngeal SCCs progress to a more aggressive phenotype. Another study concerning laryngeal carcinomas (19) also documented a higher expression in well- than in poorly/moderately-differentiated SCCs and in $\mathrm{N} 0$ rather than $\mathrm{N}^{+}$cancer cases.

Regarding the hypopharyngeal SCC, the only previous study (25) showed there was no correlation with the degree of differentiation and COX-2 expression. In this study, COX-2 was strongly expressed in the poorly-differentiated tumor. The intensity of COX-2 staining was significantly higher in the poorly-differentiated tumors than in the well/moderatelydifferentiated tumors $(\mathrm{p}=0.039)$. Therefore, COX-2 may be related to tumor growth and differentiation as well as the early tumor phenotype.

The prognosis of hypopharyngeal carcinoma is worse than other head and neck cancers in spite of advances in surgery, radiotherapy and chemotherapy. Furthermore, the QOL of the patients frequently decreases after operations. Therefore, effective non-invasive therapy is a high priority. If COX-2 up-regulation occurs in the early stages of tumorigenesis inhibitors may be useful for prevention (16). It has been reported that selective COX-2 inhibitors inhibit cancer cell proliferation and induce apoptosis in colon, bladder and esophageal adenocarcinomas $(10,13,28,33)$. An investigation of a head and neck squamous carcinoma cell line (34) showed a similar suppression of tumor growth caused by antiangiogenesis, cell cycle arrest and inhibition of the telomerase activity of the tumor cells. Moreover, it has been shown that COX-2 inhibitors enhance the radiosensitivity of the surviving cells $(18,33)$.

Since the COX-2 expression was found to gradually increase from normal epithelium, through dysplasia to poorly differentiated SCC, but without any clear link to prognosis, its importance may be related to tumor growth. COX-2 inhibitors may therefore be beneficial, particularly for patients with dysplastic lesions in the hypopharynx and/or persistent chronic inflammation due to heavy drinking or smoking. 


\section{Acknowledgements}

This work was supported by a Grant-in-Aid for Young Scientists (B))(18791211) from the Ministry of Education, Culture, Sports, Science and Technology of Japan.

\section{References}

1. Vane JR, Bakhle YS and Botting RM: Cyclooxygenases 1 and 2. Annu Rev Pharmacol Toxicol 38: 97-120, 1998.

2. Smith WL and Song I: The enzymology of prostaglandin endoperoxide $H$ synthases- 1 and -2 . Prostaglandins Other Lipid Mediat 68-69: 115-128, 2002.

3. Giovannucci E, Egan KM, Hunter DJ, Stampfer MJ, Colditz GA, Willett WC and Speizer FE: Aspirin and the risk of colorectal cancer in women. N Engl J Med 333: 609-614, 1995.

4. Schreinemachers DM and Everson RB: Aspirin use and lung, colon and breast cancer incidence in a prospective study. Epidemiology 30: 138-146, 1994.

5. Eberhart CE, Coffey RJ, Radhika A, Giardiello FM, Ferrenbach S and DuBois RN: Up-regulation of cyclooxygenase-2 gene expression in human colorectal adenomas and adenocarcinomas. Gastroenterology 107: 1183-1188, 1994.

6. Fux R, Schwab M, Thon KP, Gleiter CH and Fritz P: Cyclooxygenase-2 expression in human colorectal cancer is unrelated to overall patient survival. Clin Cancer Res 11: 4754-4760, 2005.

7. Hida T, Yatabe Y, Achiwa H, et al: Increased expression of cyclooxygenase-2 occurs frequently in human lung cancers, specifically in adenocarcinomas. Cancer Res 58: 3761-3764, 1998

8. Mohammed SI, Knapp DW, Bostwick DG, et al: Expression of cyclooxygenase-2 (COX-2) in human invasive transitional cell carcinoma (TCC) of the urinary bladder. Cancer Res 59: 5647-5650, 1999.

9. Nozoe T, Ezaki T, Kabashima A, Baba H and Maehara Y: Significance of immunohistochemical expression of cyclooxygenase-2 in squamous cell carcinoma of the esophagus. Am J Surg 189: 110-115, 2005.

10. Zhi H, Zhang J, Zhou C, et al: Significance of COX-2 expression in human esophageal squamous cell carcinoma. Carcinogenesis 27: 1214-1221, 2006.

11. Yang GZ, Ding HY and Zhou JS: Cyclooxygenase-2 is overexpressed in Chinese esophageal squamous cell carcinoma and correlated with NF-кB: An immunohistochemical study. Exp Mol Pathol 79: 214-218, 2005.

12. Heeren P, Plukker J, Dullemem HV, Nap R and Hollema H: Prognostic role of cyclooxygenase-2 expression in esophageal carcinoma. Cancer Lett 225: 283-289, 2005.

13. Zimmermann KC, Sarbia M, Weber AA, Borchard F, Gabbert HE and Schror K: Cyclooxygenase-2 expression in human esophageal carcinoma. Cancer Res 59: 198-204, 1999.

14. Maaser K, Daubler P, Barthel B, et al: Oesophageal squamous cell neoplasia in head and neck cancer patients: Up-regulation of COX-2 during carcinogenesis. Br J Cancer 88: 1217-1222, 2003.

15. Chan G, Boyle JO, Yang EK, et al: Cyclooxygenase-2 expression is up-regulated in squamous cell carcinoma of the head and neck. Cancer Res 59: 991-994, 1999.

16. Nathan CAO, Leskov IL, Lin M, Abreo FW, Shi R, Hartman GH and Glass J: COX-2 expression in dysplasia of the head and neck. Cancer 92: 1888-1895, 2001.

17. Erovic BM, Pelzmann M, Turhani D, et al: Differential expression pattern of cyclooxygenase- 1 and -2 in head and neck squamous cell carcinoma. Acta Otolaryngol 123: 950-953, 2003.
18. Chen WC, McBride WH, Che SM, et al: Prediction of poor survival by cyclooxygenase- 2 in patients with $\mathrm{T} 4$ nasopharyngeal cancer treated by radiation therapy: clinical and in vitro studies. Head Neck 27: 503-512, 2005

19. Kawata R, Hyo S, Maeda T, Urade Y and Takenaka H: Simultaneous expression of cyclooxygenase-2 and microsomal prostaglandin E synthase in squamous cell carcinoma of the larynx. Acta Otolaryngol 126: 627-632, 2006.

20. Cho EI, Kowalski DP, Sasaki CT and Haffty BG: Tissue microarray analysis reveals prognostic significance of $\mathrm{COX}-2$ expression for local relapse in T1-T2N0 larynx cancer treated with primary radiation therapy. Laryngoscope 114: 2001-2008, 2004.

21. Ranelletti FO, Almadori G, Rocca B, et al: Prognostic significance of cyclooxygenase- 2 in laryngeal squamous cell carcinoma. Int J Cancer 95: 343-349, 2001

22. Bayazit YA, Buyukberber S, Sari I, et al: Cyclooxygenase-2 expression in laryngeal squamous cell carcinoma and its clinical correlates. ORL 66: 65-69, 2004.

23. Renkonen J, Wolff $\mathrm{H}$ and Paavonen T: Expression of cyclooxygenase-2 in human tongue carcinoma and its precursor lesions. Virchows Arch 440: 594-597, 2002.

24. Chang BW, Kim DH, Kowalski DP, Burleson JA, Son YH, Wilson LD and Haffty BG: Prognostic significance of cyclooxygenase-2 in oropharyngeal squamous cell carcinoma. Clin Cancer Res 10: 1678-1684, 2004

25. Peng JP, Su CY, Chang HC, Chai CY and Hung WC: Overexpression of cyclo-oxygenase-2 in squamous cell carcinoma of the hypopharynx. Hum Pathol 33: 100-104, 2002.

26. France M, Drew PA, Dodd T and Watson DI: Cyclooxygenase-2 expression in esophageal adenocarcinoma as a determinant of clinical outcome following esophagectomy. Dis Esophagus 17: 136-140, 2004.

27. Shamma A, Yamamoto H, Doki Y, et al: Up-regulation of cyclooxygenase- 2 in squamous carcinogenesis of the esophagus. Clin Cancer Res 6: 1229-1238, 2000.

28. Yu HP, Shi LY, Lu WH, Su YH, Li YY and Xu SQ: Expression of cyclooxygenase-2 (COX-2) in human esophageal cancer and in vitro inhibition by a specific COX-2 inhibitor, NS-398. Gastroenterol Hepatol 19: 638-642, 2004.

29. Gallo O, Masini E, Bianchi B, Bruschini L, Paglierani M and Franchi A: Prognostic significance of cyclooxygenase-2 pathway and angiogenesis in head and neck squamous cell carcinoma. Hum Pathol 33: 708-714, 2002.

30. Ratnasinghe D, Tangrea J, Roth MJ, et al: Expression if cyclooxygenase- 2 in human squamous cell carcinoma of the esophagus; an immunohistochemical survey. Anticancer Res 19: 171-174, 1999

31. Chen J, Wang LS, Wang PH, et al: High cyclooxygenase-2 expression in cervical adenocarcinomas. Gynecol Oncol 88: 379-385, 2003

32. Kyzas PA, Stefanou D and Agnantis NJ: COX-2 expression correlates with VEGF-C and lymph node metastases in patients with head and neck squamous cell carcinoma. Mod Pathol 18: 153-160, 2005

33. Ruegg C, Zaric J and Stupp R: Non-steroidal anti-inflammatory drugs and COX-2 inhibitors as anti-cancer therapeutics: hypes, hopes and reality. Ann Med 35: 476-487, 2003.

34. Nishimaru G, Yanoma S, Mizuno H, Kawakami K and Tsukuda M: A selective cyclooxygenase- 2 inhibitor suppresses tumor growth in nude mouse xenografted with human head and neck squamous carcinoma cells. Jpn J Cancer Res 90: 1152-1162, 1999. 